International Journal of Current Advanced Research

ISSN: O: 2319-6475, ISSN: P: 2319 - 6505, Impact Factor: SJIF: 5.995

Available Online at www.journalijcar.org

Volume 6; Issue 4; April 2017; Page No. 3098-3101

DOI: http://dx.doi.org/10.24327/ijcar.2017.3101.0192

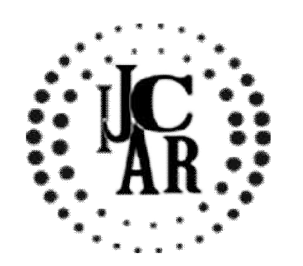

Review Article

\title{
NON INVASIVE METHODS OF SEDATION IN PAEDIATRIC DENTISTRY-A REVIEW
}

\section{Ruksana Sheik and Shanmugaavel A.K}

Department of Paedodontics, Saveetha Dental College, Chennai

\begin{tabular}{l}
\hline A R T I C L E I N F O \\
Article History: \\
Received $17^{\text {th }}$ January, 2017 \\
Received in revised form $8^{\text {th }}$ February, 2017 \\
Accepted $22^{\text {nd }}$ March, 2017 \\
Published online $28^{\text {th }}$ April, 2017 \\
\end{tabular}

Key words:

Sedation, Oral, Midazolam, Intranasal, Inhalation

\begin{abstract}
A B S T R A C T
Aim: To do a review on the different non invasive methods of sedation in paediatric dentistry

Objective: To learn the advantages and disadvantages of the different techniques of sedation.

Background: Dental anxiety and fear of the dental treatment have been recognised as a source of problems in children management which can affect the quality of the treatment. The dental procedure can be easily done with the help of sedation in these children. Procedural sedation is the administration of sedative or dissociative agents, with or without analgesics, to induce a state that allows the children to tolerate unpleasant procedures while maintaining cardio respiratory function.

Reason: To know about the various techniques of sedation which helps us to manage the uncooperative children and elicit a successful treatment.
\end{abstract}

Copyright $\bigcirc 2017$ Ruksana Sheik and Shanmugaavel A.K. This is an open access article distributed under the Creative Commons Attribution License, which permits unrestricted use, distribution, and reproduction in any medium, provided the original work is properly cited.

\section{INTRODUCTION}

Management of children during dental procedures is a major challenge for the dentists. The behavioural problems are encountered in children younger than six years of age due to factors like immature reasoning, limited coping skills and anxiety/fear resulting from lack of experience. [1] Most dental anxiety develops in childhood as a result of frightening and painful dental experiences. If appropriate precautions are not taken, dental treatment may overwhelm the child, resulting in dental fear and avoidance. [2] A successful dental treatment in anxious and fearful children mainly depends upon successfully gaining their cooperation. Use of sedation can be very helpful in allying apprehension and minimizing an uncooperative child's attempt to resist the treatment. [3, 4] The primary use of pharmacological sedation is to alter or eliminate negative behavior and allow the child to cooperate [5] and improve the patient's behavior, minimize the negative psychological response toward treatment by reducing anxiety, reduce apprehension, and maximize amnesia potential so as to control behavior during dental procedure. [6]

Procedural conscious sedation includes providing an adequate level of sedation to decrease pain and anxiety, maximize amnesia, monitoring and governing behavior, and sustaining a stable cardiovascular and respiratory status. The various routes of administration of sedation to the children includes oral, nasal, inhalational, rectal, subcutaneous, intramuscular

*Corresponding author: Ruksana Sheik

BDS 3rd Year, Saveetha Dental College, Chennai and intravenous routes. [7] Safe and efficient sedation is important in obtaining high-quality imaging studies in children. Sedation practices can vary among different hospitals. [8]

\section{Non invasive routes of sedation}

\section{Oral route}

Oral sedation is the most common route of administration among pediatric dentists. $[9,10]$ However, this route may be unpredictable, and frustration often arises when children refuse to accept the sedative medication. [9, 11] The oral route is the oldest and most economical of all routes of drug administration. It is also the most universally accepted method. Most practitioners prefer the oral route of drug administration due to high safety, very few complications and can be easily accepted by the children. In addition, parents also prefer this less invasive method of drug administration. [12] Other advantages of oral drug administration include no specialized training required, minimum equipment utilized and low incidence of adverse reactions. [13] Oral route of administration is useful in needle phobic young children who cannot cope with dental treatment as well as patients with learning difficulties or other medical conditions. However, the oral intake of the drug is completely dependent on the compliance of the child patient and determination of the appropriate dosage is difficult. [14] Therefore, oral sedation is probably the most widespread form of sedation used in dentistry. [13] However, there are also some disadvantages associated with the oral route, which include dependence upon patient compliance, delayed onset of drug action, inability to titrate drug dose and difficulty in administrating a 
reversal agent or emergency drug in the lack of a patent intravenous line. Some other disadvantages of oral route are unpredictable outcome of the drug, inconsistency in drug absorption across the gastrointestinal mucosa and hepatic first pass effect. $[15,16]$

\section{Oral midazolam}

The clinical use of midazolam is largely used a as premedication/sedation drug. One of the limiting factors in the use of midazolam for sedation is the shorter duration of action. [17] So, midazolam can be used effectively in pediatric patients for short, less painful and minimally invasive procedures. [18] Midazolam has been used orally at doses between $0.2-1.0 \mathrm{mg} / \mathrm{kg}$ with onset of action between 20-30 minutes. [19,20,21]. Singh et al found that oral midazolam in a dose of $0.5 \mathrm{mg} / \mathrm{kg}$ is suitable premedication for child patients (ASA Category I) during short dental procedures. [20]. Another study compared two dosages of oral midazolam $(0.3 \mathrm{mg} / \mathrm{kg}$ or $0.5 \mathrm{mg} / \mathrm{kg})$ in 31 physically and neurologically compromised pediatric (3-18 years) dental patients; both dosages proved successful, without intraoperative or postoperative complications. [22]. Saarnivaara et al recommended oral midazolam dose of 0.5 $\mathrm{mg} / \mathrm{kg}$ for children less than five years and $0.4 \mathrm{mg} / \mathrm{kg}$ for older children. [23] Ma et al concluded that oral midazolam in the doses between $0.5-1.0 \mathrm{mg} / \mathrm{kg}$ can be a safe and acceptable sedation drug especially in children over 3 years of age. [24]. Somri et al compared three doses of oral midazolam, between 0.5 to $1.0 \mathrm{mg} / \mathrm{kg}$ in $3-10$ year old children, with conclusion that $0.75 \mathrm{mg} / \mathrm{kg}$ appears to be the optimal dose in terms of effectiveness and safety. [25] Wilson et al. performed a randomized, controlled cross-over trial on the effectiveness of $0.5 \mathrm{mg} / \mathrm{kg}$ oral midazolam sedation for orthodontic extraction of permanent teeth and they concluded that oral sedation with midazolam was safe and acceptable in 10-16 year old patients. [26]

There can also be side effects associated with the use of midazolam. The major risk associated with high doses of midazolam is hypoventilation and associated hypoxemia. [27] Some studies have reported that administration of higher oral midazolam doses $(0.75$ or $1.0 \mathrm{mg} / \mathrm{kg})$ may result in a greater incidence of side effects such as loss of balance and head control, blurred vision and dysphasia as compared with placebo or $0.5 \mathrm{mg} / \mathrm{kg}$ of midazolam. [28] Dionne reported that oral midazolam at doses of 0.75 to $1.0 \mathrm{mg} / \mathrm{kg}$ produced a incidence of side effects and decreased respiration manifesting as oxygen saturation values below $80 \%$ in some children. [29] Withdrawal phenomena may occur in children after prolonged use. [30]

\section{Inhalation route}

Inhalation sedation is a reliable and easy route of drug administration. The drugs delivered through this route have a very rapid onset and short recovery period. Their effect may be rapidly reversed by reducing the concentration of the agent or discontinuing it entirely and administering only oxygen. [31] One of the most popular sedation modalities used by paediatric dentists is the use of nitrous oxide (N2O) and oxygen (O2) alone or in conjunction with midazolam. [32] and it is considered to be the ideal sedation technique for use in paediatric dentistry. [33].
The technique of inhalation sedation with nitrous oxide/oxygen is an efficient method of reducing fear, anxiety and pain and improving patient co-operation in both children and adults. The term 'inhalation sedation' describes the induction of a state of conscious sedation by administering subanaesthetic concentrations of gaseous anaesthetic agents. [34] This technique is successfully employed in the provision of dental treatment for extractions. [35]

Advantages of Inhalation Sedation includes non invasiveness, drug level may easily be altered or discontinued, titration - it is easy to vary the level of sedation, rapidly absorbed, rapid onset within 2-3 minutes and a peak of 3-5 minutes, rapidly eliminated from the body, rapid and complete recovery within 5 minutes, minimal impairment of any reflexes, thus protecting the cough reflex. [34]

Disadvantages of Inhalation Sedation includes lack of potency, dependent largely on psychological reassurance, gas must be administered continuously via a mask close to the operation site, nasal seal may be broken during patient movement rendering the sedation less effective and exposing staff to nitrous oxide, nasal hood may interfere with injections in the anterior maxillary region, patient must be able to nose breathe for the sedation to be effective, nasal hood may be rejected by a patient, particularly one with a previous history of GA, Nitrous oxide pollution, extent of postoperative amnesia is very variable. [34]

\section{Intranasal route}

The intranasal method of sedation is a painless, needleless procedure that does not require intravenous catheters. [36] Intranasal drug delivery results in direct medication absorption, while avoiding hepatic first-pass metabolism making more drug available more rapidly when compared with other routes. [37] Intranasal midazolam has been found to be effective when used for moderate sedation and as a premedicant. [38, 39] A study by Fukuta et al.19 found that no patient rejected the nasal mask or refused to inhale $\mathrm{N} 2 \mathrm{O} / \mathrm{O} 2$ subsequent to intranasal administration of midazolam. [40] Intranasal sedation using midazolam has been found to be highly useful when providing dental care for uncooperative pediatric dental patients. [38] Children sedated with intranasal midazolam are passive and moderately drowsy but usually do not fall completely asleep. The average time to peak plasma concentrations and maximal effect is $10 \mathrm{~min}$. $[41,42,43]$ and recovery time is approximately $30 \mathrm{~min}$, with the degree of the sedative effect similar to that obtained with IM administration. [44]

Although intranasal administration is usually simple, relatively painless, and requires less patient cooperation, it has been associated with mucosal irritation. This may lead to coughing, sneezing, crying and the expulsion of part of the dose. This is particularly true when a large volume of the drug is applied. [40, 38] Therefore it should be administered carefully.

\section{Rectal route}

Rectal midazolam has been studied as a preanaesthetic medication for children $[45,46]$ and the optimal sedative dose was determined to be $1.0 \mathrm{mg} / \mathrm{kg}$. [45] Most drugs, however, are not as well-absorbed rectally as from the upper intestine. [47] Rectal administration of midazolam has been demonstrated to be effective and safe for sedating child 
patients, with an onset of action of as short as five minutes [48, 49]. However, interruption of absorption by defecation and lack of patients' and parents' acceptance are major disadvantages of rectal midazolam [38].

\section{References}

1. Henry RJ, Jerrell RG. Ambient nitrous oxide levels during pediatric sedations. Pediatr Dent 1990; 12: 8791.

2. Locker D, Liddell A, Dempster L, Shapiro D. Age of onset of dental anxiety. J Dent Res. 1999;78:790-796.

3. Lanza V, Mercadante S, Pignataro A. Effects of halothane, enflurane, and nitrous oxide on oxyhemoglobin affinity. Anesthesiology 1988; 86: 591594.

4. Field LM, Dorrance DE, Krzeminska EK, Barsoum LZ. Effect of nitrous oxide on cerebral blood flow in normal humans. Br J Anaesth 1993; 70: 154-159.

5. McComb M, Koenigsberg SR, Broder HL, Houpt M. The effect of oral conscious sedation on future behaviour and anxiety in paediatric dental patients. Pediatr Dent 2002; 24:207-11.

6. Cote CJ Todres D, Goudsouzian NG, Ryan JF. A practise of anaesthesia for infant and children. 3rd ed. Philadelphia: WB Saunders; 2001. p. 584-609

7. Mistry, R.B., Nahata, M.C., 2005. Ketamine for conscious sedation in pediatric emergency care. Pharmacother. J. Human Pharmacol. Drug Ther. 25, 1104-1111.

8. Keeter S, Benator RM, Weinberg SM, Hartenberg MA. Sedation in pediatric CT: national survey of current practice. Radiology 1990;175:745-752

9. Chopra R, Mittal M, Bansal K, Chaudhuri P. Buccal midazolam spray as an alternative to intranasal route for conscious sedation in pediatric dentistry. $J$ Clin Pediatr Dent. 2013; 38:171-173.

10. Primosch RE, Guelmann M. Comparison of drops versus spray administration of intranasal midazolam in two- and three-year-old children for dental sedation. Pediatr Dent. 2005; 27:401-408.

11. Bahetwar SK, Pandey RK, Saksena AK, Chandra G. A comparative evaluation of intranasal midazolam, ketamine and their combination for sedation of young uncooperative pediatric dental patients: a triple blind randomized crossover trial. J Clin Pediatr Dent. 2011; 35:415-420.

12. Ryder W, Wright PA. Dental sedation. A review. $\mathrm{Br}$ Dent J 1988; 165: 207-216.

13. Malamed SF, Quinn CL. Sedation: a guide to patient management. 3rd ed. St. Louis: Mosby Year Book. 1995: 99-137.

14. Hosey MT, Fayle S. Pharmaceutical prescribing for children. Part 5. Conscious sedation for dentistry in children. Prim Dent Care. 2006; 13(3):93-6.

15. Dionne R, Trapp LD. Oral and rectal sedation. In: Dionne RA, Phero JC, Becker DE. Management of pain and anxiety in the dental office. 1st ed. WB Saunders Company 2002: 225-234.

16. Braham RL, Bogetz MS, Kimura M. Pharmacologic patient management in pediatric dentistry: an update. ASDC J Dent Child 1993; 60: 270-280.

17. Sievers TD, Yee JD, Foley ME, Blanding PJ, Berde CB. Midazolam for conscious sedation during pediatric oncology procedures: safety and recovery parameters. Pediatrics 1991;88: 1172-1179.

18. Walbergh EJ, Wills RJ, Eckhert J. Plasma concentrations of midazolam in children following intranasal administration. Anesthesiology 1991; 74: 233-235.

19. Kupietzky A, Houpt MI. Midazolam: a review of its use for conscious sedation of children. Pediatr Dent 1993; 15: 237-241.

20. Singh N, Pandey RK, Saksena AK, Jaiswal IN. A comparative evaluation of oral midazolam with other sedatives as premedication in pediatric dentistry. $J$ Clin Pediatr Dent 2002; 26:161-164.

21. Houpt M, Giovannitti JA. Pediatric sedation. In: Dionne RA, Phero JC, Becker DE. Management of pain and anxiety in the dental office. 1st ed. WB Saunders Company. 2002: 296-314.

22. Silver T, Wilson C, Webb M. Evaluation of two dosages of oral midazolam as a conscious sedation for physically and neurologically compromised pediatric dental patients. Pediatr Dent 1994; 16: 350-359.

23. Saarnivaara L, Lindgren L, Klemola UM. Comparison of chloral hydrate and midazolam by mouth as premedicants in children undergoing otolaryngological surgery. Br J Anaesth 1988; 61: 390-396.

24. Ma L, Jing Q, Wan K. Evaluation of oral midazolam sedation for reducing dental fear in children with dental fear. Hua Xi Kou Qiang Yi Xue Za Zhi 2012; 30: 271274.

25. Somri M. Parisionos CA, Kharouba J et al. Optimizing the dose of oral midazolam sedation for dental procedures in children: a prospective, randomized, and controlled study. Int J Paediatr Dent 2012; 22: 271279.

26. Wilson KE, Welbury RR, Girdler NM. A study of the effectiveness of oral midazolam sedation for orthodontic extraction of permanent teeth in children: a prospective, randomised, controlled, crossover trial. $\mathrm{Br}$ Dent J. 2002; 192(8):457-62.

27. Dock M, Creedon RL. Pharmacological management of patient. In: McDonald RE, Avery DR. Dentistry for the Children and Adolescent. 8th ed. St. Louis, CV Mosby 2004: 285-311.

28. McMillan CO, Spahr-Schopfer 1A, Sikich N, Hartley E, Lerman J. Premedication of children with oral midazolam. Can J Anaesth 1992; 39: 545-550.

29. Dionne R. Oral sedation. Compend Contin Educ Dent 1998; 19: 868-874.

30. Kain, Z.N., Hofstadter, M.B., Mayes, L.C., Krivutza, D.M., Alexander, G., Wang, S., Reznick, J.S., 2000. Midazolam: effects on amnesia and anxiety in children. Anesthesiology 93, 676-684.

31. Bennett CR: Conscious Sedation in Dentistry. Quintessence International. 1978;5-8.

32. Shapira J, Holan G, Botzer E, Kupietzky A, Tal E, Fuks AB. The effectiveness of midazolam and hydroxyzine as sedative agents for young pediatric dental patients. ASDC J Dent Child 1996; 63:421-425.

33. Malamed SF. Sedation: a guide to patient management. 4th edn. St Louis: CV Mosby Co, 2003:525-543.

34. Paterson, SUSAN A., and JINOUS F. Tahmassebi. "Paediatric dentistry in the new millennium: 3 . Use of 
inhalation sedation in paediatric dentistry." Dent Update 30.7 (2003): 350-6

35. Blain K, Hill F. The use of inhalation sedation and local anaesthesia as an alternative to general anaesthesia for dental extractions in children. Br Dent $J$ 1998; 184: 608-611

36. AlSarheed, Maha A. "Intranasal sedatives in pediatric dentistry." Saudi Medical Journal 37.9 (2016): 948

37. Lee-Kim SJ, Fadavi S, Punwani I, Koerber A. Nasal versus oral midazolam sedation for pediatric dental patients. J Dent Child (Chic) 2004; 71: 126-130.

38. Fuks AB, Kaufman E, Ram D, Hovav S, Shapira J. Asssesment of two doses of intranasal sedation of young pediatric dental patients. Pediatr Dent 1994; 16:301-305.

39. Wilton NC, Leigh J, Rosen DR, Pandit UA. Preanesthetic sedation of preschool children

40. Fukuta O, Braham RL, Yanase H, Kurosu K. The sedative effects of intranasal midazolam administration in the dental treatment of patients with mental disabilities. Part 2: optimal concentration of intranasal midazolam. J Clin Pediatr Dent 1994; 18:259-265.

41. Rose E, Simon D, Haberer JP: Premedication with intranasal midazolam in pediatric anesthesia. Ann Fr Anesth Reanim 9:326-30, 1990 (French).

42. Latson LA, Cheatham JP, Gumbiner CH, Kugler JD, Danford DA, Hofschire PJ, Honts J: Midazolam nose drops for outpatient echocardiography sedation in infants. Am Heart J 121:209-10, 1991.
43. Bunz R, Gossler M: Intranasal premedication of young children using midazolam (Dormicum): Clinical experience. Anasthesiol Intensivmed Notfallmed Schmerzther 26:76-8, 1991 (German).

44. de Santos P, Chabas E, Valero R, Nalda MA: Comparison of intramuscular and intranasal premedication with midazolam in children. Rev Esp Anestesiol Reanim 38:12-15, 1991 (Spanish).

45. Spear RM, Yaster M, Berkowitz ID, Maxwell LG, Bender KS, Naclerio R, Manolio TA, Nichols DG: Preinduction of anesthesia in children with rectally administered midazolam. Anesthesiology 74:670-74, 1991.

46. Roelofse JA, Van der Bijl P, Stegmann DH, Hartshorne JE: Preanesthetic medication with rectal midazolam in children undergoing dental extractions. $J$ Oral Maxillofac Surg 48:791-96, 1990.

47. Wynn RL: General principles of drug action. In Clinical Pharmacology in Dental Practice, 4th Ed. SV Holroyd, RL Wynn, B Requa-Clark, EDS. St. Louis: CV Mosby Co, 1988, pp 12.

48. Saint-Maurice C, Meistelman C, Rey E, Esteve C, de Lauture D, Olive G. The pharmacokinetics of rectal midazolam for premedication in children. Anesthesiology. 1986; 65(5):536-8.

49. Roelofse JA, Stegmann DH, Hartshorne J, Joubert JJ. Paradoxical reactions to rectal midazolam as premedication in children. Int J Oral Maxillofac Surg. 1990; 19(1):2-6.

\section{How to cite this article:}

Ruksana Sheik and Shanmugaavel A.K (2017) ' Non Invasive Methods of Sedation In Paediatric Dentistry-A Review', International Journal of Current Advanced Research, 06(04), pp. 3098-3101.

DOI: http://dx.doi.org/10.24327/ijcar.2017.3101.0192 